\title{
Textile Material Lessons Learned During the Design and Qualification of the NASA Orion Capsule Parachute Assembly System
}

\author{
Brian P. Anderson ${ }^{1}$, Jared Daum ${ }^{2}$ \\ NASA Johnson Space Center, Houston, TX, 77058, USA \\ Sarah Tawdros ${ }^{3}$ \\ Airborne Systems North America, Santa Ana, CA, 92704, USA
}

\begin{abstract}
The NASA Orion Capsule Parachute Assembly System (CPAS) development and qualification testing was completed in September 2018. Over the course of the airdrop and ground testing campaign, the team benefited from the ability to design, test, and adjust the design based on observations and inspection results. While the design team used the best knowledge available and attempted to utilize best practices, a number of lessons were learned that should be documented for consideration by future designers. This paper describes these lessons learned including the use of textile reefing loops, the importance of performing joint tests, the impact of using bight sleeves on parachute deployment, and a surprising number of design changes required in the CPAS system after the decision was made to change the suspension line braid to save system mass.
\end{abstract}

\section{Introduction}

The nominal NASA Orion parachute system developed by the Capsule Parachute Assembly System (CPAS) team is composed of three mortar-deployed Forward Bay Cover Parachutes (FBCPs), two mortar-deployed drogue parachutes, three mortar-deployed pilot parachutes, and three pilot-deployed main parachutes. The CPAS concept of operations for a nominal mission is depicted in Figure 1. As part of the development and certification of the parachute system, a total of 25 system air drop tests were conducted including 17 development tests and 8 qualification tests. This testing was carried out between September 2011 and September 2018. On average, one airdrop test was executed every 100 days. During development testing, the design of the system frequently evolved as data was reviewed and updates were made to make the system more reliable. Changes were made less frequently during the qualification testing phase. Many of the design updates related to the textile materials in the system and resulted in significant lessons learned. This paper describes a sampling of these lessons learned over the course of the entire CPAS test campaign.

${ }^{1}$ CPAS Project Manager, Project Management Branch (EA5-2), AIAA Member.

${ }^{2}$ CPAS Hardware Lead, Flight Mechanics and Trajectory Design Branch (EG-5).

${ }^{3}$ Project Engineer. 


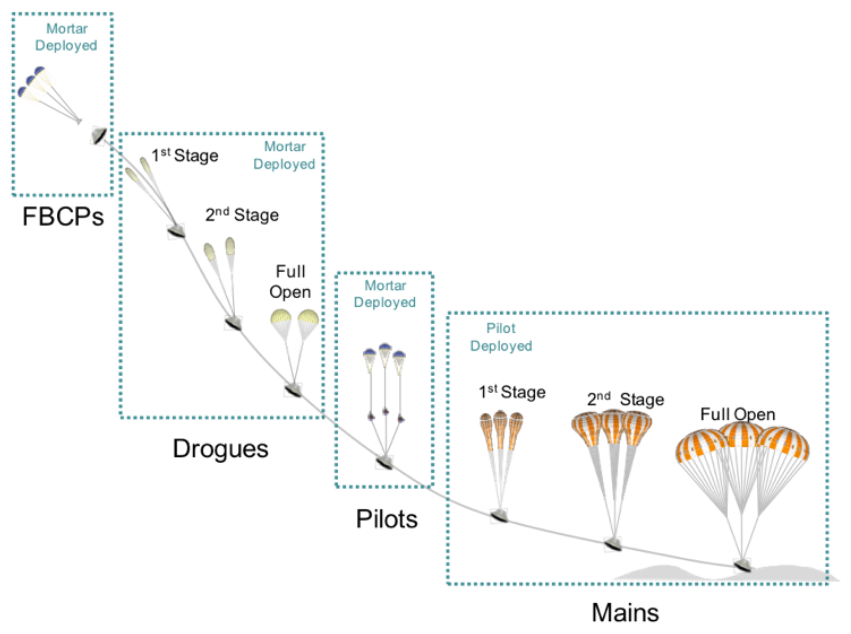

Figure 1 Nominal CPAS concept of operations.

\section{Use of Textile Materials in the CPAS Design}

Textile materials are a natural choice for use in parachute systems because of their large strength-to-weight ratio and the ability to pack textiles into various shapes for integration into parachute compartments. In the CPAS system, there are only 3 metallic components. These components include the vehicle attach fittings that provide the interface between the spacecraft and the parachute, a metallic link that connects the pilot parachute to the main deployment bag, and the reefing line cutter assembly.

The FBCPs are used to help pull the Forward Bay Cover through the mid-field wake after jettison from the Crew Module. They are made primarily of Kevlar, have a trailing distance of approximately 100 feet, and have a maximum mass of $8.5 \mathrm{lbm}$. These parachutes are pressure packed to a maximum density of approximately $36 \mathrm{lbm} / \mathrm{ft}^{3}$. The drogue parachutes are used to decelerate and stabilize the vehicle prior to pilot/main deployment. They are fabricated using both Kevlar and nylon, have a trailing distance of just over 100 feet, and have a maximum mass of $64 \mathrm{lbm}$. These parachutes are pressure packed to a maximum density of approximately 33 $\mathrm{lbm} / \mathrm{ft}^{3}$. The pilot parachutes are used to extract the main parachutes from the parachute compartment and deploy the main parachutes. They are fabricated using both Kevlar and nylon, have a trailing distance of just under $70 \mathrm{feet}$, and have a maximum mass of $9.0 \mathrm{lbm}$. These parachutes are hand-packed to a maximum density of approximately $33 \mathrm{lbm} / \mathrm{ft}^{3}$. Finally, the main parachutes are also fabricated primarily of Kevlar and nylon, have a trailing distance of 230 feet and an approximate mass of $260 \mathrm{lbm}$. They are pressure packed to a density of approximately $42 \mathrm{lbm} / \mathrm{ft}^{3}$. The suspension lines in the three main parachutes have a total length of approximately 10 miles.

Several challenges exist with the use of textile materials. For example, sometimes certain material properties are unknown or are difficult to gather. This is especially true for some textile stiffness properties in a relevant parachute deployment environment. While static stiffness properties can readily be gathered in a normal lab setting, gathering dynamic stiffness properties is more challenging. In addition, due to the chaotic, sometimes unrepeatable nature of parachute deployment and operation, it sometimes requires many test cycles ("demands") before a design can be deemed adequate. Several examples of this and other textile-related challenges will be 
presented throughout this paper. These include the use of textile reefing loops, the importance of joint testing, the use of bight sleeves, textile risers, and challenges CPAS encountered when updating to a new suspension line weave.

\section{Textile Reefing Loops}

The parachute reefing system is used to "permit an incremental opening of a parachute canopy"' 11 and protects both the parachute and the spacecraft from excessive loads. A textile reefing line is used to constrain the canopy for a prescribed amount of time before the reefing line is cut. A reefing loop or ring serves as the interface between the parachute structure (typically the radial at the canopy skirt) and the reefing line. The original design of the CPAS main and drogue parachutes included metallic reefing rings. Following initial development airdrop tests and upon inspection of the rings and the canopy, some damage was noted to both the reefing rings and the textile material surrounding the rings. While no damage was ever observed that substantially affected parachute performance, the design team felt that a switch to textile reefing loops was important based partially on the work by Hennings[2].

The switch to textile reefing loops was made first on the main parachute design. As part of the CPAS airdrop test program, a pallet was used to extract the test article from the aircraft $[3,4]$. To ensure a safe landing for the pallet, "retired" CPAS main parachutes were used as pallet recovery parachutes. The benefit of using retired main parachutes for this purpose was that the team could make updates to the recovery parachutes to evaluate the appropriateness of proposed design changes to the flight system. The team incorporated textile reefing loops into the pallet recovery parachutes starting on CDT3-4. The textile reefing loops were incorporated into the flight main parachutes on CDT3-8. A figure showing textile reefing loops for the main parachute design is shown in Figure 2. At reefing line cutter locations, a bypass loop (also seen in Figure 2) is used to route the reefing line for the other reefing stage above the reefing line cutter. From CDT3-8 through the end of the qualification airdrop test program, only minor damage was noted on the main parachute reefing loops.

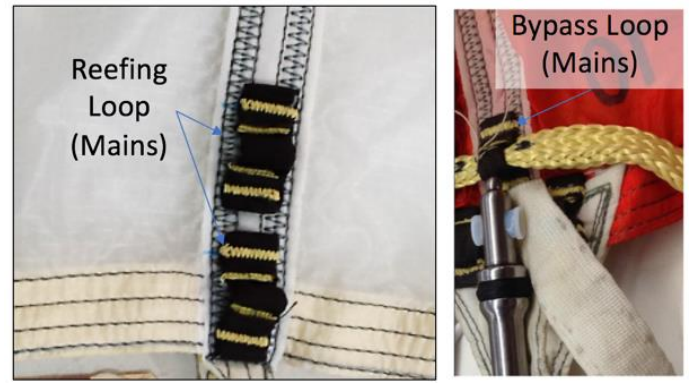

Figure 2 Main parachute reefing loops \& bypass loop

Reefing loops were not incorporated on the drogue design until relatively late in the test campaign. The design was first included in an airdrop test on CDT3-15 and the design did not have the benefit that the main parachutes had of being used on pallet recovery parachutes. One reason for the design update was that the drogue mortar vendor requested that the parachute volume inside the mortar be reduced to mitigate mortar firing reaction loads. The reduced parachute volume inside the mortar increased the risk that there would be unacceptable damage due to packing on the reefing rings or the surrounding material. 
Figure 3 shows the drogue reefing loop design. The drogue reefing loops wrap around the radial, whereas the main reefing loops are attached to the inside of the radial (Figure 2). A bypass loop is used to route the other stage reefing line around the reefing line cutter. A cotton tie is used to hold the reefing line in place. The cotton tie pierces the reefing line and is tied around the reefing loop. See Figure 4. These cotton ties are also used on the main parachutes.
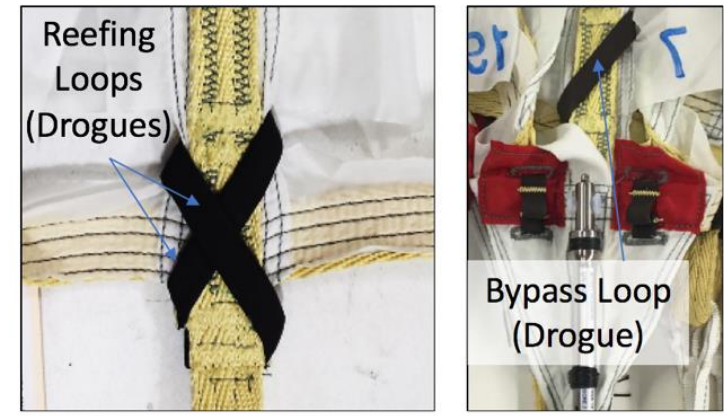

Figure 3 Drogue parachute reefing loops \& bypass loop

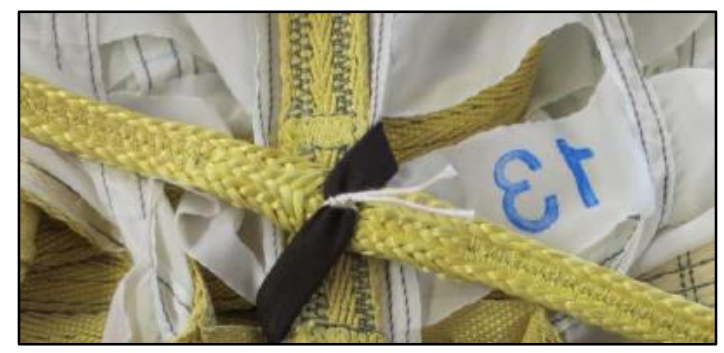

Figure 4 Cotton tie at bypass loop

During post-flight inspections of one of the two drogues used on the CQT4-6 airdrop test, it was noted that one of the drogue bypass reefing loops had failed. The cause of the failure appeared to be abrasion followed by a tensile failure of the few remaining fibers. Inspections indicated that the abrasion was caused by relative motion between the reefing line and bypass loop. Review of the test video showed the failure took place 7 seconds into the 8 second stage as evidenced by a parachute skirt shape change. A similar failure was also observed in the CQT4-8 airdrop test. During this test the failure took place between 5.1 and 5.8 seconds into the 8 second stage. There were no noticeable effects on parachute drag performance on either CQT4-6 or CQT4-8. While some reefing loop abrasion had been noted on previous drop tests, none of this damage had caused major concern because some abrasion to the reefing loops is expected once the reefing cutters fire and the reefing line is pulled through the reefing loops.

In order to understand the failure cause and to determine the overall risk to the drogue design, a fault tree analysis was conducted. Possible causes or contributors to the failure included defective materials, parachute re-use, parachute environments, insufficient design, reefing line cutter environment sensors, and improper installation or packing. After a rigorous investigation, it was determined that the primary root cause of the failure was an insufficient reefing loop design. Re-use was also considered as a potential contributor, although the exact mechanism for this contribution is unknown. 
The specific failure mode was determined to be migration of the reefing line to the corner of the reefing loop with subsequent sawing in the drop test vehicle wake. Analysis showed that it is likely that the cotton ties meant to hold the reefing line in the middle of the bypass loop failed prematurely. Then, due to the canopy shape and the direction of force on the reefing line, the reefing line was pulled down into the corner of the bypass loop. As illustrated in Figure 5, there is an angle formed due to the bypass that encourages the reefing line to migrate to the corner of the bypass loop. Ground testing showed that when the reefing line was in the corner of the bypass loop that it was very easy to saw through the loop, while sawing in the middle of the loop would not lead to loop failure.

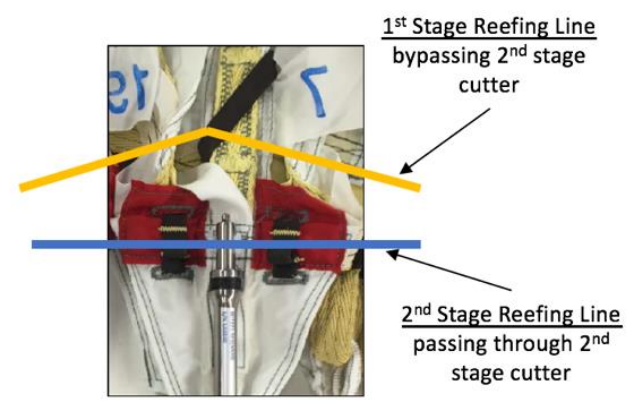

Figure 5 Bypass loop angle illustration

Additional analysis showed that while it is somewhat likely that a single reefing loop may fail on future flights, it is unlikely that the failure will propagate to cause a failure of other reefing loops. A bounding analysis also showed that even in the event that all the reefing loops failed (essentially a skipped-stage scenario), parachute margins were sufficient to not cause concern.

At this point in the project lifecycle, the CPAS team recommended no change to the baseline design and the recommendation was accepted by the Orion Program. It was deemed that the risk was acceptable and since no additional airdrop tests are planned for the CPAS system, any unintended consequences due to design updates could not be adequately vetted. However, future designers should pay particular attention to the angles cause by bypass loop designs and consider more robust reefing line retention methods (while taking into consideration that the retention device needs to break at the completion of staging). As CPAS incurred sawing only at the bottom corner of the loop, designers should take care to prevent this type of edge loading. The CPAS team also could have benefited from modifying "retired" drogue parachutes earlier in the test campaign for use as test-support (programmer) parachutes. This opportunity would have provided additional demands against potential drogue flight-design updates.

\section{Joint Testing and Backstitching}

Nearly every parachute is fabricated or assembled by sewing components of various types together. For example, on a ribbon parachute a nylon ribbon and a Kevlar load radial are sewn together to form a joint. Whenever textiles are connected together using sewing, a loss in strength occurs relative to the basic material strength[1]. This reduction in strength is called a "joint efficiency". The joint efficiency values are typically determined by strength testing[5], although simulations have also been used[6]. Determining the joint efficiency is an important part of understanding parachute component margins of safety. Although parachutes are loaded in 
a dynamic manner, per standard practice CPAS applies the results from slow-speed ("static") pull tests in margin of safety calculations.

As noted in Ref[5], there were 92 joint tests required to determine joint efficiencies for the CPAS design. This was a major effort in that it required 920 tests. For each joint, 5 samples each were fabricated by different operators on different sewing machines. However, the wealth of data obtained showed that "the requirement for implementing two or more sets of operators and sewing machines is not necessary if the overall standards for quality of training, manufacturing, and inspection are high"[7]. CPAS uses the "standard efficiency"[5,7] for margin of safety calculation purposes.

One particular joint location in the CPAS system resulted in significant work and resources. At each reefing line cutter location, there is a reefing line cutter lanyard that is used to activate the cutter at parachute line stretch. The lanyard is created by inserting a formed loop of Kevlar cord into the suspension line by means of finger traps where the tail ends are placed in two adjacent locations. The result of the separate locations causes an additional external loop that is secured with a straight-stitch to prevent the insertion from unraveling prior to loading. During inspection of the EM-1 main parachute suspension lines it was noted that the straight stitching had begun to unravel and the insertion was loose. None of the straight-stitches had been backstitched". Backstitching is a locking method accomplished by sewing both the beginning and end of the straight stitch in the opposing direction for a short distance. It is meant to prevent unraveling. Further investigation revealed that the samples used in joint testing for certifying the joint did not contain back-stitching either.

This information was discovered just prior to EM-1 parachute packing and the CPAS team was very cognizant of delivery schedules to Kennedy Space Center (KSC). Parachute component strength margins had been reported to the Orion Program and showed positive margins for the suspension lines (using the joint test results using the samples without a back stitch). Specifically, the joint without backstitching had an efficiency of $82 \%$ and the suspension line margin was $+11 \%$ using the CPAS requirements. Partially due to schedule awareness, and partially due to the belief that updated joint testing would provide results that would maintain strong positive margins, the CPAS project pressed ahead with EM-1 parachute packing in parallel with the updated joint tests. The main parachutes were packed and delivered on time to KSC.

The follow-on joint tests with the backstitch included resulted in a lower efficiency than anticipated. This brought the suspension line margin to essentially $0 \%$ against the CPAS requirements. The extra stitching due to the backstitch weakened the base material more than predicted. However, the CPAS requirements are written for crewed missions for which abort scenarios are possible. Abort environments are the stressing cases for the main parachutes. Because EM-1 is not crewed, will not include abort capabilities, and EM-1 specific parachute margins were positive, the team felt comfortable pressing ahead without a costly unpacking and re-packing of the main parachutes.

Ultimately, following a great deal of testing, an updated EM-2 design was derived that ensures the straight stitch does not unravel by hand-tying the loose ends of the stitch instead of using a 
backstitch. The updated design resulted in healthier margins against CPAS requirements and the design was implemented on the last 6 parachute airdrop tests.

The CPAS team learned that sometimes joint testing results are surprising. While it seemed ahead of time that the backstitching would only result in a small decrease in efficiency, the team in retrospect should have performed the joint testing prior to parachute packing.

\section{Bight Sleeves}

In order to promote orderly deployment, the main parachute deployment bag is designed with several compartments. The first compartment contains the parachute canopy. Additional compartments separate suspension lines and parachute riser. A series of weak ties are used to keep the suspension lines organized and untangled. As the 80 suspension lines are routed across the bag, they are folded to form a "bight" and weak ties are used tie the bight to beckets on the deployment bag. Locking stow loops are attached to the main deployment bag walls just underneath the compartment flaps. The locking stow loops are routed through reinforced holes designed into the compartment flaps. These locking stows are used to help keep the compartment flaps closed until the appropriate time during deployment. As the flaps are closed, suspension lines bights are placed in the locking stow loops. During deployment, the suspension lines are pulled out of the stow loops, allowing the compartment flaps to open.

During parachute inspections following the CDT3-5, it was noted that several main parachute suspension lines experienced unexpected damage. The damage appeared to be consistent with abrasion or snagging. The most severe damage was concentrated on 2 lines. Photographs representative of the damage are shown in Figure 6. This degree of suspension line damage had not been observed previously on CPAS development tests. Damage was also observed on two locking stow loops.

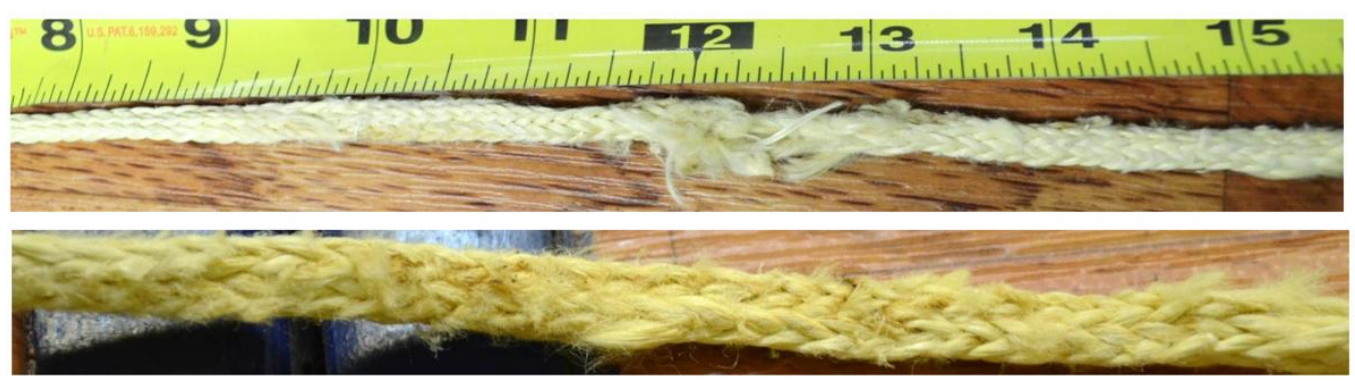

Figure 6 Suspension line damage following CDT3-5

While the root cause was never positively identified, it was believed to have been caused by interaction between suspension lines and adjacent locking stow loops. During packing, it is possible that some of the suspension lines in one of the bights were inadvertently routed over an adjacent stow loop, as modeled in Figure 7. In order to prevent this from happening in the future, a design update was made to wrap the suspension line bights with a Spectra sleeve to prevent "stray" suspension lines from interacting with stow loops or other snag hazards. The bight sleeves were comprised of a single piece of rectangular Spectra fabric. During packing, the suspension lines were wrapped with the bight sleeve with a small amount of overlap before the bight was placed in the locking stow. These bight sleeves were only applied in locations that passed through a locking stow loop. The bight sleeves were intended to immediately release and 
drift away upon deployment as nothing is left to retain the sleeve around the bight of lines after being pulled from the loop. This change was first implemented on one main parachute on CDT39 and all main parachutes from CDT3-10 and on. Following this design update, the suspension line damage seen after CDT3-5 was never observed again.

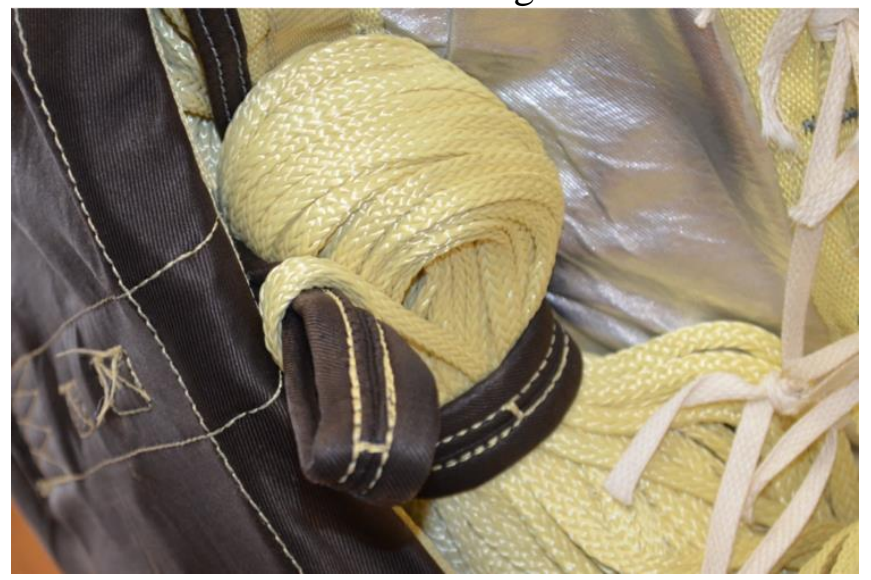

Figure 7 Possible suspension line \& locking stow interaction on CDT3-5

During video reviews of main parachute deployment on CQT4-5, there were several "false confluences" identified. Figure 8 shows a series of photos as the drop test progressed. False confluences are locations where the suspension lines are restricted and the parachute is not allowed to attain it's intended shape. Each of these false confluences were temporary in that the suspension lines eventually released and deployment and parachute staging were successful. Upon closer review of the video it was noted that the white Spectra bight sleeves were still present on the suspension lines throughout first stage. The bight sleeve was only able to release given the parting force induced from first stage disreef. While many of the sleeves released immediately upon deployment and could be observed flying away from the parachute, some of the sleeves remained on the suspension lines and were the cause of the false confluences. It was also noted that some of the sleeves migrated up the suspension lines. This caused concern given that it raised the possibility that migrating bight sleeves might combine and result in a stronger restriction. Ultimately, all bight sleeves did liberate. On CQT4-5 there was a slight temporary change in parachute performance that was attributed to the bight sleeves.

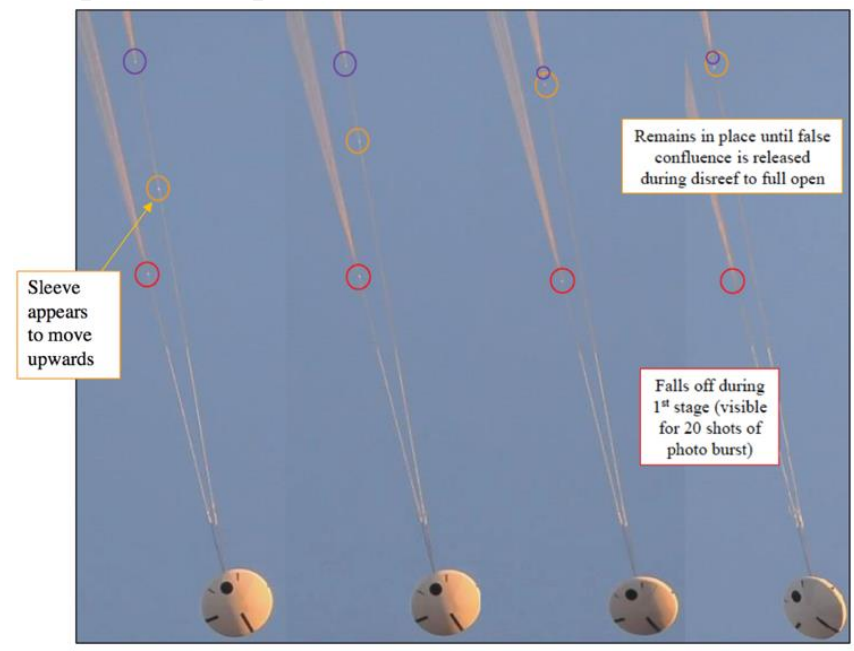

Figure 8 Bight sleeve progression on CQT4-5. Circles highlight locations with bight sleeves present. 


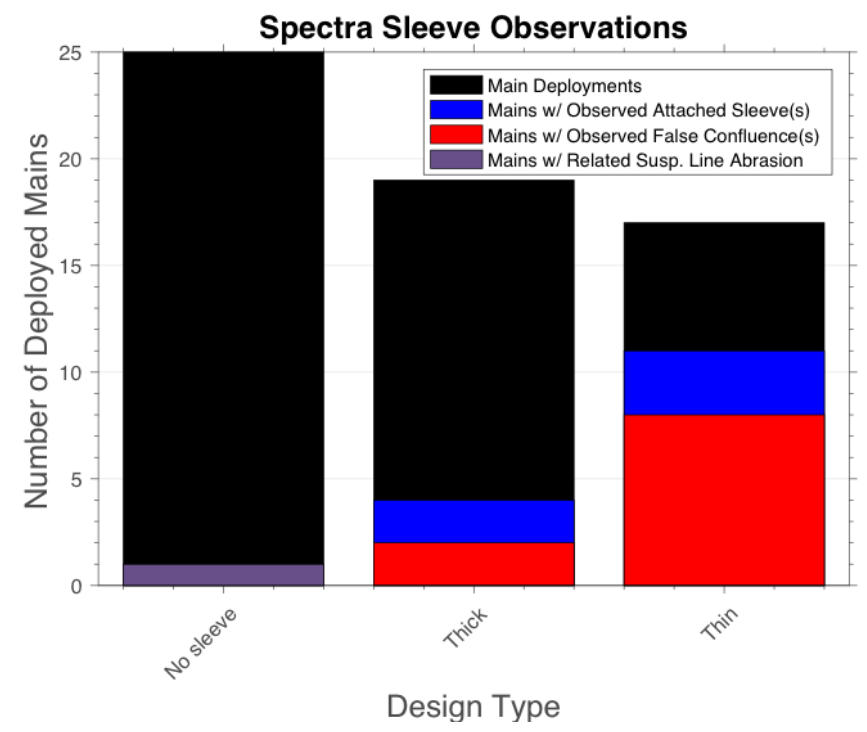

Figure 9 Bight sleeve and false confluence experience

Following the observations on CQT4-5, the team reviewed previous drop test videos again and noticed that false confluences were present on previous tests, but to a lesser extent. After reviewing all of the data it was noted that drop tests beginning with CDT3-17 (the last development test) through CQT4-6 (the sixth qualification test), were more likely to experience a false confluence. See Figure 9. As will be discussed in Section VII, on CDT3-17 the CPAS team implemented a new suspension line weave that resulted in smaller suspension lines. However, with the change to smaller suspension lines, the Spectra bight sleeve design was not modified accordingly. As such, the overlap of the Spectra wrap increased from approximately 2 -inches with the old suspension lines to 4 -inches with the new lines. It is believed that this is a key contributor to the increase in false confluence observations. Ground testing was conducted using bungee cords to simulate bight extraction through the stow loop. The testing showed that the bight sleeve material would roll over itself (similar to rolling a pair of socks) and bind. The resulting mass of material was somewhat difficult to unlock.

The false confluences caused by the bight sleeves were a cause of concern. A sustained confluence can cause a change to the geometry of the suspension lines and impact drag performance. In the worst case, a false confluence due to a bound-up bight sleeve(s) near the parachute skirt can result in the parachute failing to fully inflate, potentially causing loss of a main parachute. Ultimately, the team decided that the likelihood and consequence of sustained false confluences due to the Spectra sleeves was not acceptable for human flight. While one option was to re-size the Spectra sleeves to account for the smaller suspension lines, it was ultimately decided to remove the Spectra sleeves from the design altogether.

In retrospect, adding the bight sleeves appears to have done more harm than good due to the unintended consequences of the Spectra binding. Based on airdrop test experience, it also appears that the false confluences due to the Spectra sleeves have a higher likelihood of occurring than experiencing the suspension line damage seen on CDT3-5. From a consequence perspective, the false confluences could result in hesitation during deployment (relatively low consequence) or in a worse case could prevent parachute inflation (high consequence). In 
contrast, the damage observed on CDT3-5 would not result in a main parachute failure. Bungee ground testing without bight sleeves performed as part of the investigation also showed that the likelihood of damaging suspension lines was low. All of this rationale was used in the decision to remove bight sleeves from the design.

\section{Textile Risers}

The very earliest CPAS riser designs for the drogues and mains were comprised of Kevlar from the vehicle attach point all the way to the canopy skirt. During an Orion vehicle analysis cycle, the CPAS team was directed to change the riser segments closest to the vehicle to steel cable. This change was implemented on both the drogues and the mains. While many factors contributed, the primary reasons for making the switch were that (1) there was a perception that the steel risers were more robust against abrasion damage caused by vehicle dynamics; and (2) because Apollo successfully used steel risers. Steel risers were implemented on the first system development test (CDT3-1) through CDT3-12, including EFT-1. Steel risers were also used on CDT3-14 because the parachute compartment used for that test closely matched the EFT-1 parachute compartment and only had steel riser interfaces.

In order to protect the steel riser from sharp edges and potentially hot surfaces in the parachute compartment, extensive ground testing was performed to find suitable abrasion / thermal protective covers to install over the steel cable. In addition, several design iterations were required to determine an acceptable interface between the steel riser and the Kevlar suspension lines. It also required significant effort to integrate the steel risers into the drogue mortar canister and to integrate both the drogue and main parachute steel risers into the vehicle attach point. The steel risers were integrated nearly vertically at the vehicle attach point, but as they were routed to their respective parachutes, the risers were required to be secured close to the vehicle structure to allow the forward bay cover to be placed on the crew module. Because the steel risers had significant stored energy when pressed against the vehicle, it typically took two parachute riggers to hold the riser down as it was secured. This stored energy also required strong retention ties.

The challenges associated with the use of steel risers, along with a desire by the Orion Program to save mass, prompted a design update back to an all-textile riser design. Because steel risers were originally selected due to their perceived robustness, the team set out to find an all-textile solution that was robust. Initial tests[8] showed that such a design was possible. Following this initial testing, additional ground tests were performed at Johnson Space Center (JSC) to demonstrate abrasion robustness against several different targets. This testing showed that with protective sleeves that and all-textile riser design was at least as robust as the steel counterpart.

Switching to an all-textile riser design resulted in a parachute system mass savings of just under $60 \mathrm{lbm}$. This number accounts for the riser and the riser attach fittings. Because the vehicle interface is different for a steel and textile riser, the vehicle attach structure (referred to as the "gusset") was also redesigned and resulted in significant mass savings. A total estimated mass savings of $110 \mathrm{lbm}$ can be attributed to design updates associated with the switch to textile risers and the associated gusset updates. In addition to these mass savings, parachute packing and integration into the spacecraft became much easier and much more repeatable. The stored energy in a secured steel riser was replaced by an all-textile design that can be placed in nearly any shape, as shown in Figure 10. 


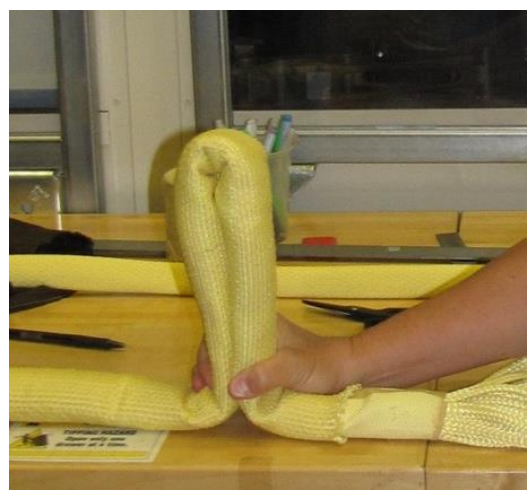

Figure 10 All-textile riser flexibility

VII. New Suspension Line Weave

As the CPAS team began system-level development tests, the team was evaluating the flight parachute design against CPAS requirements. Initial strength margin estimates for the FBCPs showed significant negative margins $(-25 \%)$ on the FBCP suspension. Several options were considered to either decrease parachute loads, make the parachute stronger, or take credit for capability already in the system. These options included reefing the canopy, updating joint designs to make them more efficient, using stronger materials, and using a custom strength specification. Because the FBCP is mortar-fired it was important to take mass and volume into consideration so as to not impact the mortar design.

In communications with the suspension line cord vendor, it was found that a different Kevlar braid could be used to help make the parachute stronger. The new braid used a weave with fewer picks per inch, while the old braid had a higher weave density. See Figure 11 for an illustration of Kevlar cord makeup and braid density. The new material was higher strength and lighter than the existing material. The primary reason for the increase in strength is that the Kevlar fibers are more oriented in the loading direction. The cost and schedule for producing the new material was virtually identical to the old material. Joint testing was performed for all the parachute joints to ensure that the new material did not result in a substantial decrease in joint efficiency. Using the new material, the FBCP suspension line was changed from $1500 \mathrm{lb}$ strength to $2250 \mathrm{lb}$ strength with no mass impacts.
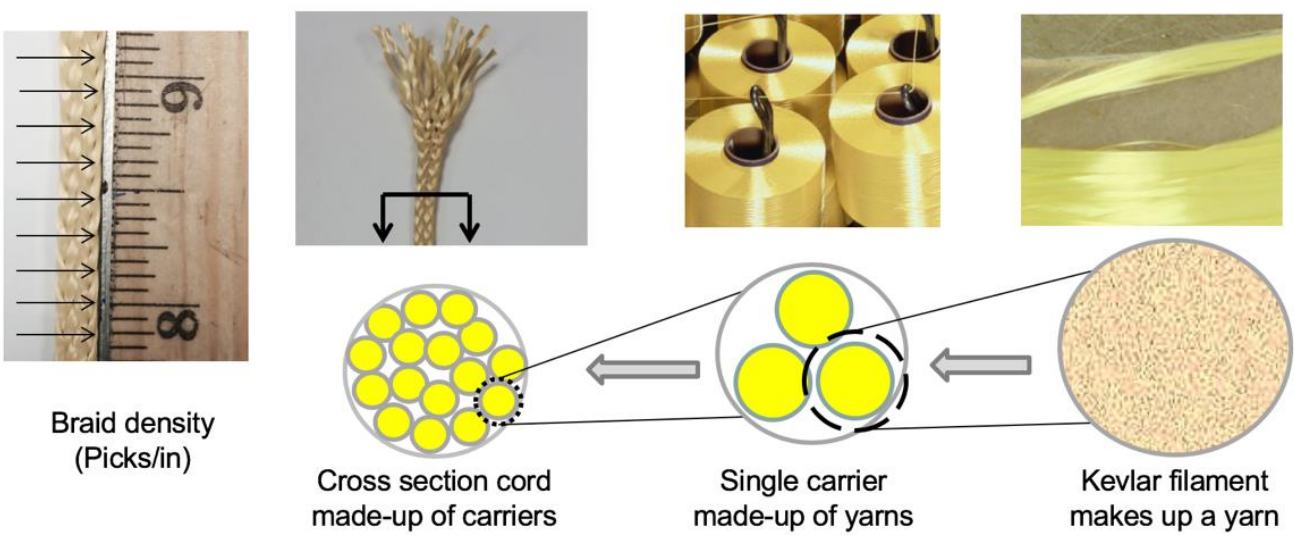

Figure 11 Kevlar cord "anatomy" 
The entire CPAS system contains many miles of suspension line. While investigating the updated FBCP suspension line weave, the team also found that the suspension lines could be updated for the mains, drogues, and pilots. In total, the suspension line design updates resulted in approximately $125 \mathrm{lbm}$ in mass savings across the CPAS system with strength increases for all cord types.

However, these design updates came with a cost. As mentioned previously, all of the parachute joints that included suspension line material needed to be retested to determine the updated joint efficiencies. Careful inspections were carried out following airdrop tests to ensure that the material was robust. Because there was less material in the weave itself, the packed parachutes also took up less volume. This was especially true for the main parachutes. A main deployment bag redesign was required and the bag height was reduced by approximately 2 -inches.

In addition, because the main deployment bag was shorter, a redesign of the main parachute retention system was also required. The retention system is comprised of Kevlar panels that are hard mounted to the parachute compartment using fasteners in pre-determined hole locations. The panels then attach to the main deployment bag to hold the parachute in place until deployment. A parachute integration using the existing retention system panels with the new, shorter deployment bag showed that the retention panels were not oriented properly (see Figure 12). The retention panels were re-sized.

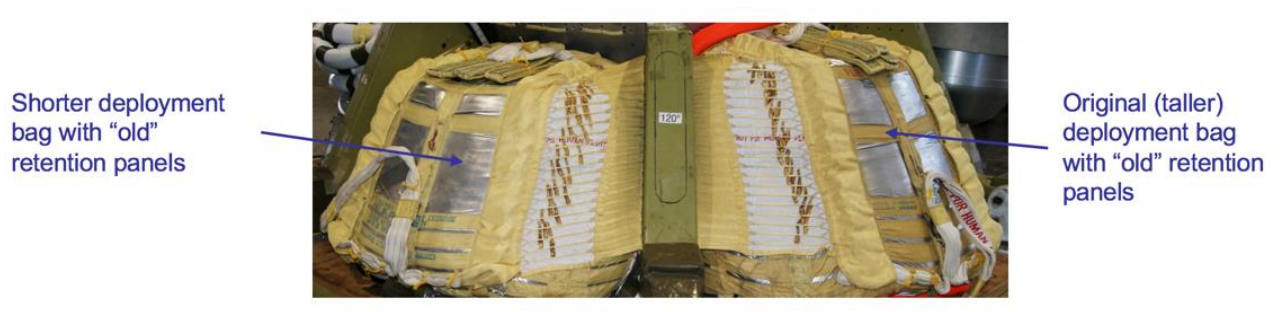

Figure 12 Comparison of retention system with shorter and original main deployment bag

The main parachute retention system also utilizes a 3-ring release strap located near the middle of the parachute bay. The function of the release strap is to ensure that the main parachute does not slide out from under the retention panels in the event of very high vehicle dynamics. With the shorter deployment bag, it was also determined that the 3-ring release strap was too long and needed to be shortened. As noted in Section V, the bight sleeve design likely should have been updated as well, although the team did not consider this until after the false confluence observations in airdrop testing. Finally, the attach fittings ("concentric pins"), which provide the interface between the riser/suspension lines and the vehicle, needed to be modified to accommodate the new, more narrow, suspension lines.

These design updates due to the suspension line weave change were costly and time consuming. Some of the required design updates were known when the decision was made to switch to the new weave, but some of them were not. Ultimately, the experience is a prime example of the law of unintended consequences. However, these updates were still worth the resources and effort given the $125 \mathrm{lbm}$ mass savings to the spacecraft. 


\section{Conclusions}

The CPAS team benefited from a relatively large number of development and qualification airdrop tests made possible by the Orion Program. Over the course of 7 years the team airdrop tested the system, learned about the design, and made updates to the design. These design updates included a number of lessons learned in dealing with textile materials. Some of these lessons were not learned on the first demand of a design but required a number of tests to truly see the merits of the udpates. In addition to the number of tests, the design updates would not have been possible without the excellent video and photographic coverage of the airdrop tests. These resources allowed the team to understand the design more fully. As with all aspects of engineering, future designers are encouraged to consider the impacts and unintended consequences of proposed design updates.

\section{Acknowledgments}

The authors thank Charles Lowry of Airborne Systems for Figure 11 and for his investigations into updating the suspension line weave. The CPAS team is also grateful to the NASA Orion Program for funding and support throughout the project.

\section{References}

[1] Knacke, T.W., Parachute Recovery Systems Design Manual, $1^{\text {st }}$ ed., Para Publishing, Santa Barbara, 1992, Chapter 5.6.

[2] Hennings, E.J., "Substitution of Reefing Loops for Reefing Rings in Pressure Packing Applications", AIAA Paper 2007-2536, May 2007.

[3] Romero, L.M., Ray, E.S., Bledsoe, K.J., Davidson, J., Varela, J.G., and Fraire, U., "Summary of CPAS EDU Testing Analysis Results", 23rd AIAA Aerodynamic Decelerator Systems Technology Conference, AIAA Paper 2015-2179, May 2015.

[4] Ray, E.S. and Morris, A., "Challenges of CPAS Flight Testing", 21st AIAA Aerodynamic Decelerator Systems Technology Conference and Seminar, AIAA Paper 2011-2557, May 2011.

[5] Mollmann, C., "Determination of Parachute Joint Factors using Seam and Joint Testing", 23rd AIAA Aerodynamic Decelerator Systems Technology Conference, AIAA Paper 2015-2125, May 2015.

[6] Roland, S., Janda, M.D., Lowry, C., "Implementation of Modeling and Simulation of Textile Seam and Joints for Parachute Design Applications", 23rd AIAA Aerodynamic Decelerator Systems Technology Conference, AIAA Paper 2015-2124, May 2015.

[7] Mollmann, C., "Strength Variation in Parachute Joints", 24th AIAA Aerodynamic Decelerator Systems Technology Conference, AIAA Paper 2017-4200, May 2017.

[8] Petersen, M., Hennings, E., Hohman, A., "Protection of a Textile Parachute Riser from Temperature and Abrasion Using a Textile Cover System”, 21st AIAA Aerodynamic Decelerator Systems Technology Conference, AIAA Paper 2011-2561, May 2011. 